Haemostasis $1994 ; 24: 263$

\title{
Contents, Vol. 24, No. 5, 1994
}

\section{Preface 264}

Ruggeri, Z.M. Pathogenesis and Classification of von WiUebrand Disease 265

Lusher, J.M. Response to 1-Deamino-8-Z)-Arginine Vasopressin in von WiUebrand Disease 276 Mannucci, P.M. Biochemical Characteristics of Therapeutic Plasma Concentrates Used in the Treatment of von WiUebrand Disease 285

Berntorp, E. Plasma Product Treatment in Various Types of von Willebrand's Disease 289 Scharrer, I.; Vigh, T.; Aygören-Pürsün, E. Experience with Haemate P in von Willebrand's Disease in Adults 298

Kreuz, W.; Mentzer, D.; Becker, S.; Scharrer, I.; Kornhuber, B. Haemate P® in Children with von Willebrand's Disease 304

I Igerslev, J. Safety of Plasma Derivatives 311 Author and Subject Index 